\title{
Mass closure on the chemical species in size-segregated atmospheric aerosol collected in an urban area of the Po Valley, Italy
}

\author{
E. Matta ${ }^{1}$, M. C. Facchini ${ }^{1}$, S. Decesari ${ }^{1}$, M. Mircea ${ }^{1}$, F. Cavalli ${ }^{1}$, S. Fuzzi ${ }^{1}$, J.-P. Putaud ${ }^{2}$, and A. Dell'Acqua ${ }^{2}$ \\ ${ }^{1}$ Istituto di Scienze dell' Atmosfera e del Clima, Consiglio Nazionale delle Ricerche, Via Gobetti 101, 40129 Bologna, Italy \\ ${ }^{2}$ European Commission, Joint Research Centre, Institute of Environment and Sustainability, Climate Change Unit, 21020 \\ Ispra, Italy
}

Received: 18 July 2002 - Published in Atmos. Chem. Phys. Discuss.: 20 November 2002

Revised: 11 March 2003 - Accepted: 30 May 2003 - Published: 5 June 2003

\begin{abstract}
A complete size segregated chemical characterisation was carried out for aerosol samples collected in the urban area of Bologna over a period of one year, using five-stage low pressure Berner impactors. An original dualsubstrate technique was adopted to obtain samples suitable for a complete chemical characterisation. Total mass, inorganic, and organic components were analysed as a function of size, and a detailed characterisation of the water soluble organic compounds was also performed by means of a previously developed methodology, based on HPLC separation of organic compounds according to their acid character and functional group analysis by Proton Nuclear Magnetic Resonance. Chemical mass closure of the collected samples was reached to within a few percent on average in the submicron aerosol range, while a higher unknown fraction in the coarse aerosol range was attributed to soil-derived species not analysed in this experiment. Comparison of the functional group analysis results with model results simulating water soluble organic compound production by gas-to-particle conversion of anthropogenic VOCs showed that this pathway provides a minor contribution to the organic composition of the aerosol samples in the urban area of Bologna.
\end{abstract}

\section{Introduction}

Atmospheric aerosol particles play an important role in the atmosphere for several reasons. They transport material through the atmosphere, affect the optical properties of the atmosphere, serve as condensation nuclei for the formation of clouds, and also take part in chemical reactions in the atmosphere.

All these processes involving atmospheric aerosols depend on the size and chemical composition of the particles them-

Correspondence to: S. Fuzzi

(s.fuzzi@isac.cnr.it) selves. Thus, efforts have been made over the years to elucidate the chemical composition of atmospheric aerosols as a function of size, and to achieve mass closure on the chemical species for the whole mass of aerosol collected. This is by no means a trivial task, as can be seen from the results of the few investigations reported in literature on the issue (Heintzenberg, 1998; Neususs et al., 2000; Putaud et al., 2000; Temesi et al., 2001). The elucidation of the organic component of the aerosol has been the most difficult task so far in achieving chemical mass closure.

Until recently, knowledge on the chemical composition of aerosols was restricted to the inorganic component, while little was known on the composition of their organic fraction (see Jacobson et al., 2000, for a review on organic atmospheric aerosols). To date, we know that organic compounds constitute a substantial fraction of the aerosol mass, up to $70 \%$, especially in the submicron size range (Saxena and Hildemann, 1996; Jacobson et al., 2000). The total amount of organic carbon (OC) within aerosol is usually determined by Evolved Gas Analysis (EGA) whereby heating the sample causes the evolution of the organic compounds, oxidised to $\mathrm{CO}_{2}$, which is then measured (Cadle et al., 1980; Huntzicker et al., 1982; Novakov et al., 1997; Cachier et al., 1989; Chow et al., 1993; Putaud et al., 2000). After quantification of aerosol OC, the traditional analytical approach to OC speciation has usually been the solvent extraction of collected aerosol particles, followed by Gas ChromatographyMass Spectroscopy (GC-MS) analysis for individual compound speciation. In spite of the large number of compounds detected (sometime several hundreds), on average less than $10 \%$ of fine aerosol OC mass has been attributed to specific compounds by this procedure (see e.g. Rogge et al., 1993).

In a previous work (Decesari et al., 2001), we specifically addressed the seasonal trend of water soluble organic aerosol in the Po Valley, an area in northern Italy affected by strong anthropogenic activities, employing a new procedure based on functional group analysis which is able to account for

(C) European Geophysical Society 2003 


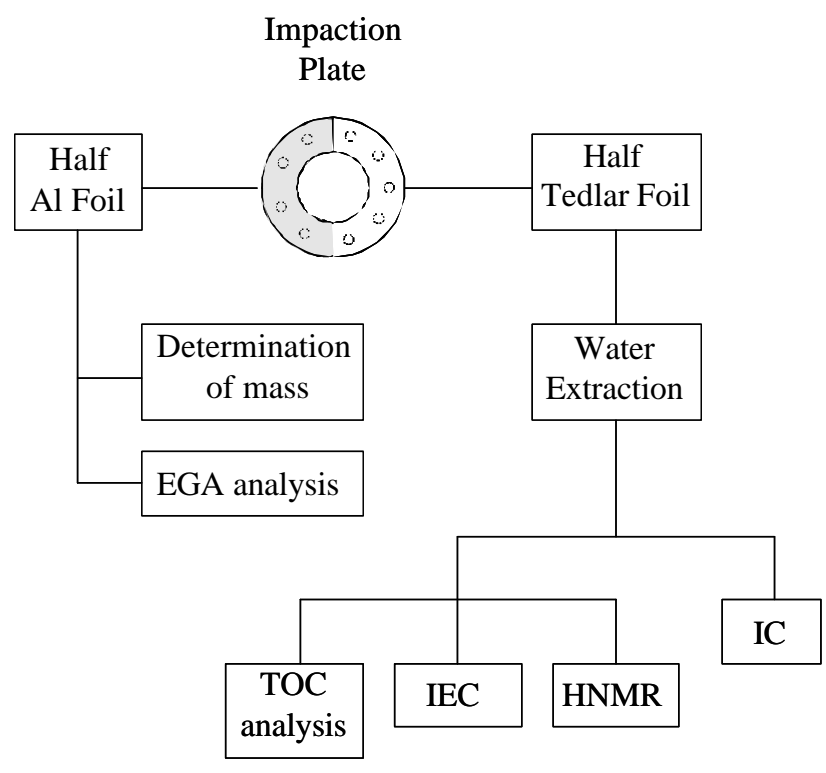

Fig. 1. Scheme of the dual-substrate technique employed for the impactor samplings and of the sample handling and analysis.

80-90\% of the water soluble organic compound mass (Decesari et al., 2000). In the present paper, we extend our study to the size segregated composition of aerosols, and to the possibility to achieve the mass closure on the chemical species of the aerosol in the different size fractions.

\section{Experimental part}

\subsection{Aerosol sampling}

The sampling was carried out on the roof of the ISAC Institute building at ca. $18 \mathrm{~m}$ height above the ground. The Institute is located in the northern outskirts of the city of Bologna, ca. $3.5 \mathrm{~km}$ from the city centre.

Sampling was performed using an $801 \mathrm{~min}^{-1}$ five-stage Berner cascade impactor (LPI 80/0.05) in the following size ranges: (1) $0.05-0.14 \mu \mathrm{m}$; (2) $0.14-0.42 \mu \mathrm{m}$; (3) $0.42-$ $1.2 \mu \mathrm{m}$; (4) $1.2-3.5 \mu \mathrm{m}$; (5) $3.5-10 \mu \mathrm{m}$. The sampling period lasted for the whole year 2000. Thirty-four 8-hour samples were collected during this period.

Since the different analytical techniques employed for the aerosol characterisation are not compatible with any individual sampling substrate, two impactors would normally have been required for this experiment. Instead, we employed a single impactor with a double tedlar/aluminium sampling substrate (Fig. 1). The impactor plate substrate consisted of half a tedlar foil on top of an aluminium foil. On the (half) aluminium substrate, total aerosol mass was measured by weighing. In fact, the aluminium substrate can be easily conditioned and weighed with an accuracy of $2 \mu \mathrm{g}$, which is not possible with the tedlar substrate due to electrostatic charges. Aerosol total carbon/organic carbon (TC/OC) can also be measured by EGA using the aluminium substrate. On the (half) tedlar substrate, the whole water-soluble aerosol material, inorganic ions and water soluble organic carbon (WSOC), was analysed. The tedlar substrate, in fact, can easily be pre-cleaned, and exhibits very low blank values for both inorganic and organic analyses.

\subsection{Sample handling}

Prior to sampling, aluminium foils were pre-fired at $500^{\circ} \mathrm{C}$ for $4 \mathrm{~h}$. Tedlar foils were cleaned several times with Milli-Q water, sonicated for $30 \mathrm{~min}$, rinsed again with Milli-Q water and dried in a clean room for $24 \mathrm{~h}$. This cleaning procedure allowed a reduction of the blank values for both inorganic and organic analyses. For a mean sample volume of $40 \mathrm{~m}^{3}$, blank values lower than $5 \mathrm{ng} \mathrm{m}^{-3}$ were reached for all inorganic ions, except for $\mathrm{Ca}^{2+}\left(30 \mathrm{ng} \mathrm{m}^{-3}\right), \mathrm{NO}_{3}^{-}$and $\mathrm{SO}_{4}^{2-}$ $\left(20 \mathrm{ng} \mathrm{m}^{-3}\right)$; blanks for TC and OC were ca. $280 \mathrm{ngC} \mathrm{m}^{-3}$, whereas WSOC blanks were ca. $120 \mathrm{ngC} \mathrm{m}^{-3}$. After sampling the foils were stored at $0^{\circ} \mathrm{C}$ in Petri dishes until the analysis.

Aluminium foils were weighed with a microbalance (Sartorius, MC5) at $23 \pm 1{ }^{\circ} \mathrm{C}$ and $19 \pm 3 \% \mathrm{RH}$ before and after sampling. The weighing precision was $\pm 2 \mu \mathrm{g}$ and the standard variation of the aluminium blank foils was $\pm 10 \mu \mathrm{g}$ $(n=5)$.

Extraction of tedlar foils was performed with $6 \mathrm{~mL}$ of Milli-Q Organex water in an ultrasonic bath. Aliquots of the extracts were used to perform the following analyses: inorganic ions, total dissolved organic carbon and speciation of water-soluble organic compound into its main classes of species (Fig. 1).

\subsection{Total carbon and organic carbon analysis}

TC/OC analyses of the aerosol samples were performed on a small portion of the aluminium foil by evolved gas analysis (EGA). With this technique, samples are subjected to five increasing temperature plateaus up to $650^{\circ} \mathrm{C}$ in an oxygenfree carrier gas, and then in an oxygen-rich carrier gas at $650-750^{\circ} \mathrm{C}$ (Putaud et al., 2000). The evolved carboncontaining gases are converted to $\mathrm{CO}_{2}$ and measured by a non-dispersive infrared (NDIR) analyser. The carbon evolving at $T<650^{\circ} \mathrm{C}$ in the oxygen-free carrier gas is defined as $\mathrm{OC}$, while the fraction evolving at $T>650^{\circ} \mathrm{C}$ in the oxidizing carrier gas is expected to be black carbon (BC). Artefacts due to charring occurred when analysing the samples collected on aluminium foils using the above routine method. Previous intercomparisons showed that the accuracy in TC determination is better than $20 \%$. Due to basic differences among thermal methods adopted by different authors to split $\mathrm{OC}$ and $\mathrm{BC}$, and to prevent or correct charring, the accuracy in $\mathrm{BC}$ determination was estimated to be ca. $60 \%$. The charring effect was assessed for 33 samples, representative of all 


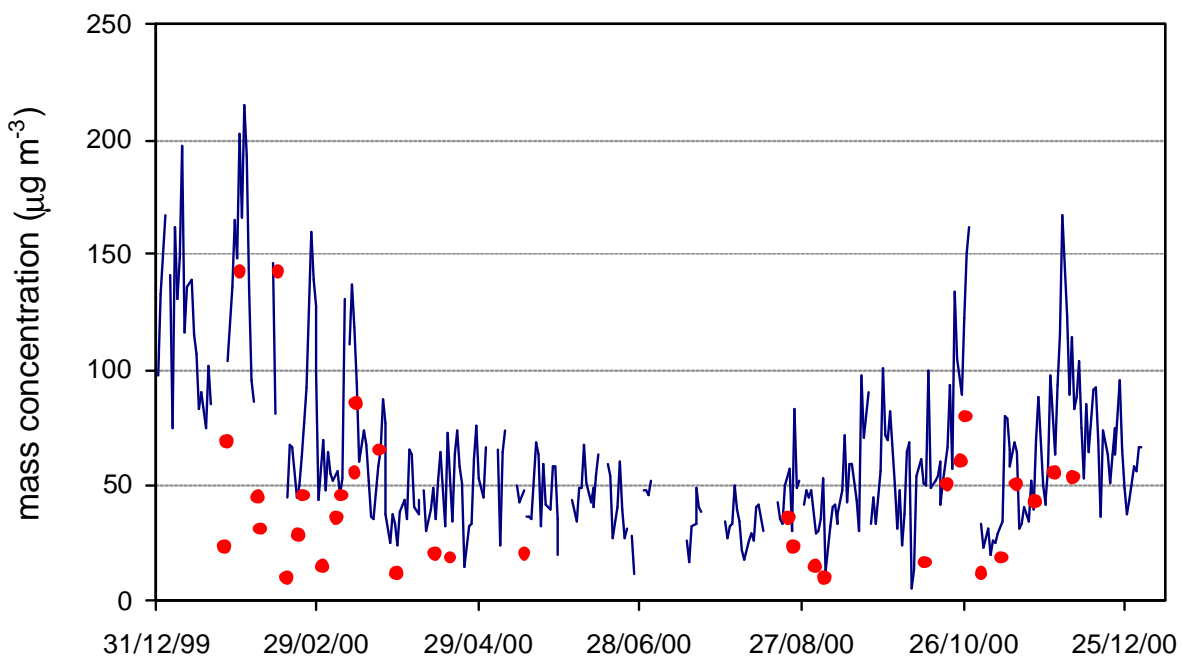

Fig. 2. Annual trend of $\mathrm{PM}_{10}$ concentration measured by the Regional Environmental Agency in the Bologna city centre (solid blue line) and the mass concentration of the impactor samples collected in this work (red dots).

size ranges and seasons, by comparing the $\mathrm{BC}$ amount obtained with the above method with the values obtained from analysis of an aliquot of sample exposed to an oxidising carrier gas at $340^{\circ} \mathrm{C}$ for $2 \mathrm{~h}$, which eliminates OC compounds responsible for charring (Cachier et al., 1989). Over these 33 samples, the ratio $B C_{\text {treated }} / B C_{\text {routine }}$ was $0.69 \pm 0.07(95 \%$ confidence level). This regression was used to correct for charring artefacts the amount of BC in the samples analysed within the present work.

\subsection{Analysis of inorganic ions}

The concentration of inorganic ions $\left(\mathrm{NH}_{4}^{+}, \mathrm{Na}^{+}, \mathrm{K}^{+}, \mathrm{Ca}^{2+}\right.$, $\mathrm{Mg}^{2+}, \mathrm{Cl}^{-}, \mathrm{NO}_{3}^{-}, \mathrm{SO}_{4}^{2-}$ ) was determined by ion chromatography (IC) in an aliquot of the tedlar foil water extract (Fuzzi et al., 1998). The detection limits of the IC analyses are well below the blank values of the filter substrates reported above, and should therefore be considered as the operational detection limits within this study. The accuracy of IC measurements was better than $5 \%$.

\subsection{Total water soluble organic carbon content}

Another aliquot of the tedlar foil water extract was used to determine the water soluble organic carbon content of the samples, using a Shimadzu TOC-5000A liquid analyser. The sample was neither acidified nor purged, to avoid loss of volatile organic compounds. According to this procedure, no distinction between water soluble organic carbon and inorganic carbon can be made for our measurements, therefore dissolved carbonates are included in the total water soluble organic carbon content. The detector response was calibrated with standard solutions of potassium hydrogen phthalate. Also in this case, the operational detection limit of the measurements should coincide with the blank values of the sampling substrate. The accuracy of the measurements ranges from $7 \%$ for $1 \mathrm{ppmC}$ solution to $3 \%$ for concentrations higher than 2 ppmC.

\subsection{Water soluble organic compounds characterisation}

Aerosol water soluble organic compounds were characterised by adopting the procedure proposed by Decesari et al. (2000), based on a combination of ion exchange chromatography (IEC), functional group investigation by Proton Nuclear Magnetic Resonance (HNMR) and total organic carbon (TOC) determination. According to this procedure, the complex mixture of water soluble organic compounds was separated by IEC into three main classes of compounds: (a) neutral compounds; (b) mono- and di-carboxylic acids; (c) polycarboxylic acids. HNMR spectroscopy was employed to analyse a single size-segregated aerosol sample, collected on 29 November. Spectra of the extracts of the five stage samples in $\mathrm{D}_{2} \mathrm{O}$ solution were acquired in a $5 \mathrm{~mm}$ probe using a Varian Mercury 400 spectrometer. Details on the experimental conditions can be found in Decesari et al. (2000).

\section{Results and discussion}

Figure 2 reports the total aerosol mass concentration, obtained by adding the measured mass of the 5 stages, for the whole sample set, superimposed on the daily-averaged $\mathrm{PM}_{10}$ measurements performed by the Regional Environmental Agency at a measuring site located in the town centre, ca. $3 \mathrm{~km}$ from our sampling site and at street level. The two sets of measurements follow the same temporal pattern, with higher concentrations in the fall-winter period and lower ones during spring-summer. In principle, given the upper 
size cut of the impactor, the two sets of data should coincide, but the impactor mass concentration values are on average $40 \%$ lower than the $\mathrm{PM}_{10}$ network measurements. This difference could be explained by the more peripheral location of our sampling site and the different sampling heights above ground. In addition, the $\mathrm{PM}_{10}$ network measurements represent daily samples, while our samples are collected over an 8 -hour period during the day.

The temporal trend of the aerosol mass concentration is similar to that in other years and that of the 1998-99 period examined in our previous study, albeit in a different location of the Po Valley (Decesari et al., 2001). Therefore, for the purpose of the present data analysis, we divided the acquired data set into two sub-sets: (i) fall-winter period (hereinafter FW, January-March and 15 October-31 December, 25 samples), when $\mathrm{PM}_{10}$ concentrations are higher, mostly above $50 \mu \mathrm{g} \mathrm{m}^{-3}$, and (ii) spring-summer period (hereinafter SS, 1 April-14 October, 9 samples), when $\mathrm{PM}_{10}$ concentrations are generally lower than this value. Four FW samples had a much lower mass concentration with respect to the average of the period, due to a rain event before sampling, and were excluded from the statistical analysis below. Unfortunately, for technical reasons, no samples were collected during the present experiment over the warmest period of June to midAugust.

\subsection{Bulk results}

In order to provide a general insight into the aerosol composition and its temporal trend, we present bulk results obtained by summing the air concentration data from each impactor stage. Minimum, median and maximum bulk concentrations for the analysed species and total aerosol weighed mass are reported in Table 1.

Carbon analyses performed on both aluminium and tedlar foils, as described in detail in the experimental part, provided total carbon concentrations (TC), apportioned between OC (organic carbon), BC (black carbon) and WSOC concentrations.

Insoluble organic carbon concentrations were determined in previous studies by subtracting WSOC from OC, under the assumption of completely insoluble BC. However, there is now evidence that a portion of $\mathrm{BC}$ is water-extractable and therefore can be included in the WSOC fraction (MayolBracero et al., 2002; Gelencsér et al., 2000). The observed partial solubility of $\mathrm{BC}$ would lead to an underestimation of the insoluble organic carbon following the above calculation. Here, we determine a water-insoluble carbon fraction (WINC) by subtracting WSOC directly from TC (WINC = TC - WSOC).

In order to include the carbonaceous species in the aerosol mass budget, conversion factors for deriving molecular mass from carbon mass are required (Turpin et al., 2000). Here we propose two distinct factors for WINC and WSOC, respectively 1.2 and 1.8 , to take into account the strict dependence
Table 1. Minimum, median and maximum bulk concentrations for the analysed species and total aerosol weighed mass. Data were obtained by summing the air concentration from each impactor stage. As explained in the text, the data are divided in two periods: fallwinter (FW) and spring-summer (SS). Total carbon (TC) was apportioned between organic carbon (OC) and black carbon (BC); water insoluble carbon (WINC) was obtained subtracting water soluble organic carbon (WSOC) directly from TC (see text). All concentration are reported in $\mu \mathrm{g} \mathrm{m}^{-3}$, except for the case of organic species (*) whose concentrations are reported in $\mu \mathrm{gC} \mathrm{m}^{-3}$

\begin{tabular}{lcccccc}
\hline & \multicolumn{2}{c}{ Min } & \multicolumn{2}{c}{ Med } & \multicolumn{2}{c}{ Max } \\
& FW & SS & FW & SS & FW & SS \\
\hline $\mathrm{NH}_{4}^{+}$ & 0.10 & 0.27 & 0.31 & 1.26 & 1.31 & 2.23 \\
$\mathrm{NO}_{3}^{-}$ & 4.27 & 0.92 & 13.29 & 2.04 & 39.04 & 4.20 \\
$\mathrm{SO}_{4}^{2-}$ & 1.54 & 0.91 & 4.55 & 2.60 & 17.04 & 5.84 \\
$\mathrm{Na}^{+}$ & 0.10 & 0.03 & 0.31 & 0.18 & 1.31 & 0.61 \\
$\mathrm{~K}^{+}$ & 0.14 & 0.05 & 0.33 & 0.10 & 0.79 & 0.23 \\
$\mathrm{Mg}^{2+}$ & 0.01 & 0.01 & 0.05 & 0.04 & 0.12 & 0.08 \\
$\mathrm{Ca}^{2+}$ & 0.30 & 0.35 & 1.16 & 0.76 & 1.75 & 1.82 \\
$\mathrm{Cl}^{-}$ & 0.15 & 0.03 & 0.79 & 0.07 & 4.90 & 0.55 \\
\hline $\mathrm{TC}^{*}$ & 6.10 & 2.62 & 12.87 & 4.52 & 34.20 & 12.57 \\
$\mathrm{OC}^{*}$ & 4.06 & 1.48 & 8.41 & 2.96 & 24.25 & 8.12 \\
$\mathrm{BC}^{*}$ & 1.86 & 1.07 & 4.13 & 1.77 & 10.49 & 4.45 \\
\hline WSOC* & 1.85 & 0.83 & 5.36 & 1.84 & 15.01 & 3.57 \\
WINC* & 2.78 & 1.64 & 6.97 & 2.93 & 19.18 & 11.52 \\
\hline Mass & 23.11 & 9.92 & 53.24 & 19.33 & 142.36 & 36.32 \\
\hline
\end{tabular}

of molecular formulas on the polarity of substances. The value adopted for WINC is derived from literature data for insoluble organic compounds (Zappoli et al., 1999). Conversely, the conversion factor for WSOC is based on their chemical characterisation in the real samples (see Sect. 3.4). Indeed, the chemical procedure for WSOC employed in this study allowed us to obtain an average composition of the water-soluble organic fraction, providing quantitative information on the concentrations of carbon, hydrogen and (indirectly) heteroatoms.

Total aerosol mass ranges from 10 to $142 \mu \mathrm{g} \mathrm{m}^{-3}$, with the highest values observed during the FW period. The maximum aerosol mass concentrations are observed on 1 and 15 February in stable weather conditions. Weather charts confirm that on those days the air mass did not change for more than $48 \mathrm{~h}$.

The main fraction of the aerosol mass is comprised of inorganic species (53\% in FW and $41 \%$ in SS), with ammonium, nitrate and sulphate together accounting for more than $80 \%$ (81\% in SS and $91 \%$ in FW, on average) of the ionic content. The percentage amount of TC is similar in the two periods (35\% in $\mathrm{FW}, 37 \%$ in SS) and a significant fraction of it is represented by WSOC (on average 50\% of TC). The 

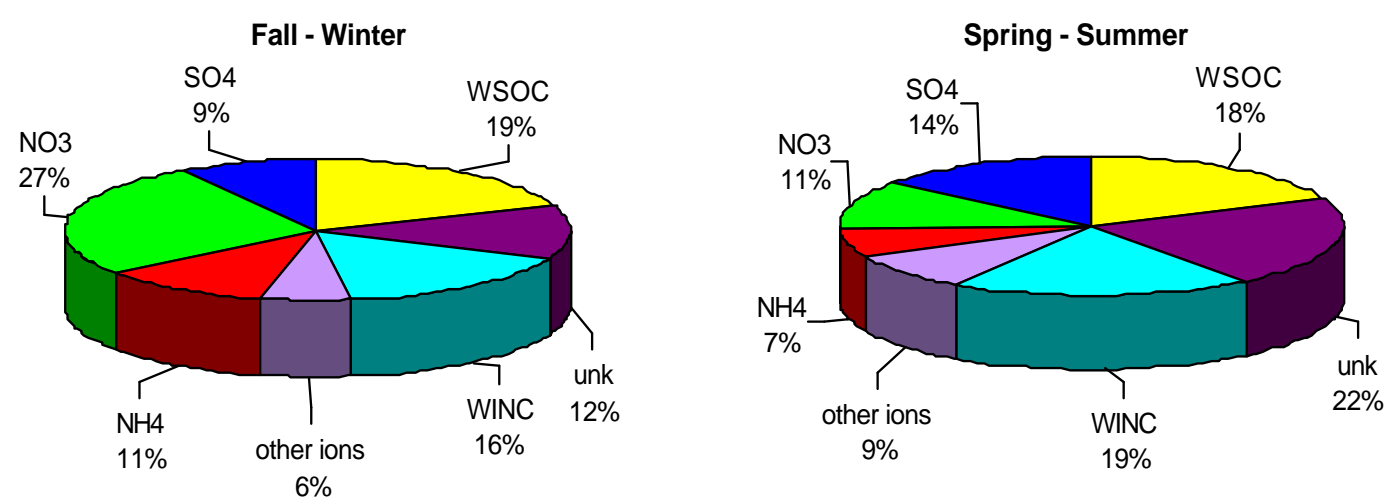

Fig. 3. Percentage contribution of inorganic compounds $\left(\mathrm{SO}_{4}^{2-}, \mathrm{NO}_{3}^{-}, \mathrm{NH}_{4}^{+}\right)$, other ions, water soluble (WSOC) and insoluble (WINC) organic species to the aerosol mass in bulk samples for the two periods fall-winter (FW) and spring-summer (SS). Unk represents percent difference between total mass measured by gravimetry and total analysed mass.

Table 2a. Minimum, median and maximum concentrations of total weighed mass $\left(\mu \mathrm{g} \mathrm{m}^{-3}\right)$ on each impactor stage (size interval) for the two periods FW and SS.

\begin{tabular}{ccccc}
\hline \multicolumn{5}{c}{ Total Weighed Mass $\left(\mu \mathrm{g} \mathrm{m}^{-3}\right)$} \\
& $\mathrm{D}(\mu \mathrm{m})$ & Min & Med & Max \\
\hline FW & $0.05-0.14$ & 1.59 & 3.40 & 8.21 \\
& $0.14-0.42$ & 4.86 & 8.85 & 20.52 \\
& $0.42-1.20$ & 7.43 & 23.45 & 88.51 \\
& $1.20-3.50$ & 1.29 & 9.82 & 26.66 \\
& $3.50-10.0$ & 2.34 & 6.52 & 16.10 \\
\hline SS & $0.05-0.14$ & 1.12 & 1.76 & 2.73 \\
& $0.14-0.42$ & 1.68 & 3.34 & 7.17 \\
& $0.42-1.20$ & 2.06 & 5.80 & 9.15 \\
& $1.20-3.50$ & 1.91 & 3.93 & 7.14 \\
$3.50-10.0$ & 2.17 & 3.79 & 11.05 \\
\hline
\end{tabular}

non-analysed mass ("unknown"), calculated as the difference between the weighed aerosol mass and the total mass of the analysed species, represents a relatively small fraction of the total weighed mass: $12 \%$ in FW and $22 \%$ in SS (Fig. 3).

\subsection{Size-segregated results}

\subsubsection{Mass concentration}

A statistical summary of mass concentration in the different size ranges is reported in Table 2a. Aerosol median mass concentrations are higher in FW than in SS in all size ranges. In both periods, the maximum value is observed at stage $3\left(23.45 \mu \mathrm{g} \mathrm{m}^{-3}-\mathrm{FW} ; 5.80 \mu \mathrm{g} \mathrm{m}^{-3}-\mathrm{SS}\right)$ and the minimum at stage $1\left(3.40 \mu \mathrm{g}, \mathrm{m}^{-3}-\mathrm{FW} ; 1.76 \mu \mathrm{g} \mathrm{m}^{-3}-\mathrm{SS}\right)$. In all samples, the greater part of total aerosol mass $(62 \%)$ is distributed in the fine size range (stages 1-3). Aerosol size distributions observed during the FW period were bimodal

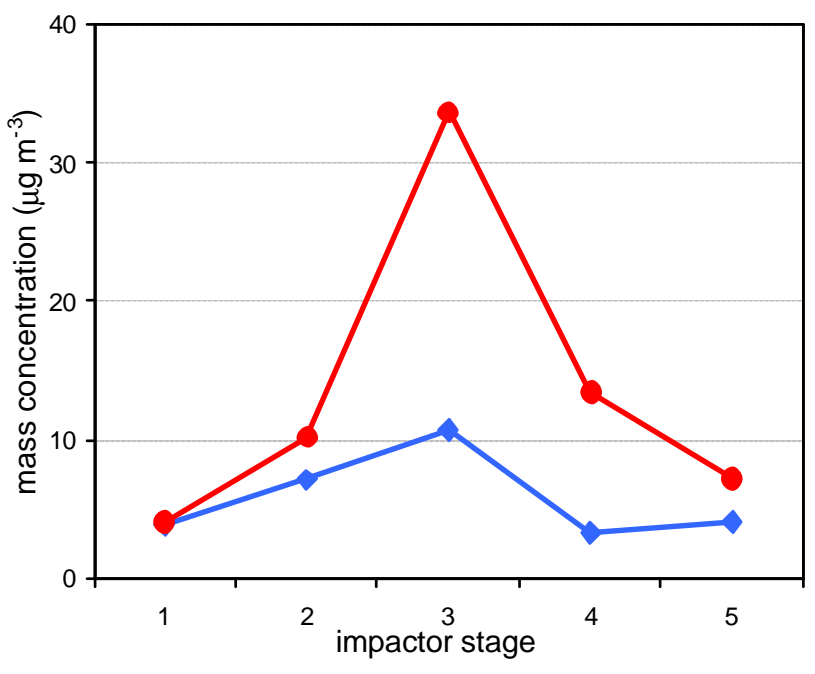

Fig. 4. Aerosol mass size distribution for the FW season. Impactor stages refer to the following size ranges: 1) $0.05-0.14 \mu \mathrm{m}$; 2) 0.14 $0.42 \mu \mathrm{m}$; 3) $0.42-1.2 \mu \mathrm{m}$; 4) $1.2-3.5 \mu \mathrm{m}$; 5) 3.5-10 $\mu \mathrm{m}$. Average concentrations for samples exhibiting bulk concentrations higher (red line) and lower (blu line) than $40 \mu \mathrm{g} \mathrm{m}^{-3}$, respectively.

or monomodal centred on the 3rd stage. This difference in mass size distribution is apparently dependent on the aerosol air concentration: a distinct coarse mode is observed at $\mathrm{PM}_{10}$ concentrations up to $40 \mu \mathrm{g} \mathrm{m}^{-3}$, whereas size distributions showing the accumulation mode alone are encountered at higher aerosol loads (Fig. 4). It follows that pollution events tend to increase the fine particle mass with respect to that of coarse particles. By contrast, the relative contribution of the coarse particles to the total aerosol mass is higher under cleaner conditions. Samples collected during the SS season showed more heterogeneous size distributions: bimodal and monomodal centred either at the 3 rd or 5th stage. On average, the fraction of coarse particles mass to total mass 
Table 2b. Minimum, median and maximum concentrations of major inorganic compounds $\left(\mu \mathrm{g} \mathrm{m}^{-3}\right)$ on each impactor stage (size interval) for the two periods FW and SS.

\begin{tabular}{ccccccccccc}
\hline & & \multicolumn{3}{c}{$\mathrm{NH}_{4}^{+}\left(\mu \mathrm{g} \mathrm{m}^{-3}\right)$} & \multicolumn{2}{c}{$\mathrm{NO}_{3}^{-}\left(\mu \mathrm{g} \mathrm{m}^{-3}\right)$} & \multicolumn{3}{c}{$\mathrm{SO}_{4}^{2-}\left(\mu \mathrm{g} \mathrm{m}^{-3}\right)$} \\
& $\mathrm{D}(\mu \mathrm{m})$ & Min & Med & Max & Min & Med & Max & Min & Med & Max \\
\hline FW & $0.05-0.14$ & 0.04 & 0.21 & 0.41 & 0.09 & 0.43 & 1.15 & 0.06 & 0.22 & 0.40 \\
& $0.14-0.42$ & 0.41 & 0.95 & 2.54 & 0.96 & 2.43 & 6.55 & 0.38 & 0.83 & 1.31 \\
& $0.42-1.20$ & 0.44 & 2.92 & 11.83 & 1.09 & 8.18 & 21.60 & 0.45 & 2.89 & 10.95 \\
& $1.20-3.50$ & 0.04 & 0.37 & 3.61 & 0.38 & 1.77 & 9.16 & 0.09 & 0.43 & 4.34 \\
& $3.50-10.0$ & 0.03 & 0.07 & 0.49 & 0.28 & 0.57 & 3.19 & 0.07 & 0.20 & 0.59 \\
SS & $0.05-0.14$ & 0.05 & 0.09 & 0.20 & 0.02 & 0.05 & 0.19 & 0.10 & 0.20 & 0.52 \\
& $0.14-0.42$ & 0.11 & 0.44 & 0.84 & 0.03 & 0.15 & 0.79 & 0.29 & 1.18 & 2.31 \\
& $0.42-1.20$ & 0.10 & 0.45 & 1.07 & 0.11 & 0.22 & 2.08 & 0.27 & 1.14 & 2.71 \\
& $1.20-3.50$ & 0.01 & 0.04 & 0.07 & 0.17 & 0.60 & 1.34 & 0.05 & 0.15 & 0.40 \\
& $3.50-10.0$ & 0.01 & 0.03 & 0.10 & 0.14 & 0.54 & 1.63 & 0.06 & 0.82 & 0.16 \\
\hline
\end{tabular}

Table 2c. Minimum, median and maximum concentrations of carbonaceous species $\left(\mu \mathrm{gC} \mathrm{m}^{-3}\right)$ on each impactor stage (size interval) and for the two periods FW and SS.

\begin{tabular}{cccccccccccccccccc}
\hline & \multicolumn{4}{c}{$\mathrm{TC}\left(\mu \mathrm{gC} \mathrm{m}^{-3}\right)$} & \multicolumn{3}{c}{$\mathrm{BC}\left(\mu \mathrm{gC} \mathrm{m}{ }^{-3}\right)$} & \multicolumn{3}{c}{ OC $\left(\mu \mathrm{gC} \mathrm{m}^{-3}\right)$} & \multicolumn{3}{c}{ WSOC $\left(\mu \mathrm{gC} \mathrm{m}{ }^{-3}\right)$} & \multicolumn{3}{c}{ WINC $\left(\mu \mathrm{gC} \mathrm{m}{ }^{-3}\right)$} \\
& $\mathrm{D}(\mu \mathrm{m})$ & Min & Med & Max & Min & Med & Max & Min & Med & Max & Min & Med & Max & Min & Med & Max \\
\hline FW & $0.05-0.14$ & 0.83 & 2.03 & 6.15 & 0.35 & 0.82 & 3.93 & 0.36 & 0.99 & 3.29 & 0.17 & 0.46 & 1.73 & 0.37 & 1.51 & 4.42 \\
& $0.14-0.42$ & 0.87 & 2.88 & 6.35 & 0.21 & 1.19 & 2.74 & 0.41 & 1.52 & 4.84 & 0.66 & 1.21 & 2.80 & 0.58 & 1.73 & 4.81 \\
& $0.42-1.20$ & 0.55 & 5.22 & 22.33 & 0.13 & 1.16 & 6.31 & 0.42 & 3.34 & 16.01 & 0.36 & 2.44 & 9.83 & 0.21 & 2.71 & 12.50 \\
& $1.20-3.50$ & 0.33 & 1.93 & 4.83 & 0.44 & 0.60 & 1.52 & 0.27 & 1.24 & 3.91 & 0.07 & 0.73 & 1.86 & 0.08 & 1.17 & 4.16 \\
& $3.50-10.0$ & 0.25 & 0.96 & 2.15 & 0.00 & 0.18 & 0.42 & 0.21 & 0.69 & 1.85 & 0.20 & 0.30 & 0.57 & 0.14 & 0.72 & 1.87 \\
\hline SS & $0.05-0.14$ & 0.44 & 0.70 & 1.09 & 0.13 & 0.35 & 0.54 & 0.20 & 0.31 & 0.76 & 0.08 & 0.18 & 0.41 & 0.31 & 0.60 & 0.92 \\
& $0.14-0.42$ & 0.74 & 1.89 & 10.15 & 0.21 & 0.57 & 3.30 & 0.27 & 0.74 & 6.85 & 0.23 & 0.46 & 1.24 & 0.29 & 1.38 & 9.86 \\
& $0.42-1.20$ & 0.52 & 1.13 & 1.94 & 0.11 & 0.53 & 0.67 & 0.41 & 0.66 & 1.64 & 0.09 & 0.50 & 1.06 & 0.38 & 0.70 & 1.21 \\
& $1.20-3.50$ & 0.27 & 0.54 & 0.86 & 0.00 & 0.07 & 0.15 & 0.25 & 0.45 & 0.80 & 0.03 & 0.22 & 0.37 & 0.05 & 0.29 & 0.60 \\
& $3.50-10.0$ & 0.35 & 0.48 & 0.90 & 0.03 & 0.05 & 0.15 & 0.31 & 0.42 & 0.85 & 0.06 & 0.24 & 0.82 & 0.07 & 0.21 & 0.58 \\
\hline
\end{tabular}

$(0.44 \pm 0.08)$ is higher than in the cold period $(0.30 \pm 0.08)$. Moreover, the coarse mode is dominant on the accumulation mode, even at the highest aerosol air concentrations measured for the period ( $36 \mu \mathrm{g} \mathrm{m}^{-3} ; 22$ August).

A bimodal distribution has already been determined in the European boundary layer at a rural site in Hungary, with a 13 stage low-pressure impactor (Temesi et al., 2001). However, Neusüss et al. (2000) measured a monomodal distribution in the Leipzig Basin, Germany, using a five-stage Berner impactor. In the same region, Heintzenberg et al. (1998) measured the aerosol mass distribution with a high-resolution apparatus (TDMPS and APS spectrometers), finding a bimodal distribution with a prevalent mode at $0.36 \mu \mathrm{m}$ (accumulation mode), and a smaller coarse mode at $2.5 \mu \mathrm{m}$. It is doubtful that the five stage Berner impactor may resolve the coarse mode under these conditions (small geomet- ric mean diameter and low concentration), thus resulting in an apparent monomodal mass distribution. Therefore, also the monomodal distribution observed in Bologna by means of the five-stage impactor cannot exclude the occurrence of a small coarse mode.

The studies cited above also tentatively established a relationship between the mass size distribution and the origin of the air masses. In the present study, the different meteorological conditions encountered during the SS period could not be well represented by the 8 samples for which a complete mass size distribution was obtained. On the contrary, the samples from the FW season discussed above are representative for stable conditions associated with weak surface circulation or short-range transport from central Europe. 
Table 2d. Minimum, median and maximum concentrations of minor inorganic compounds $\left(\mathrm{ng} \mathrm{m}^{-3}\right)$ on each impactor stage (size interval) for the two periods FW and SS.

\begin{tabular}{ccccccccccccccccc}
\hline & \multicolumn{4}{c}{$\mathrm{Na}^{+}\left(\mathrm{ng} \mathrm{m}^{-3}\right)$} & \multicolumn{3}{c}{$\mathrm{K}^{+}\left(\mathrm{ng} \mathrm{m}^{-3}\right)$} & \multicolumn{3}{c}{$\mathrm{Mg}^{2+}\left(\mathrm{ng} \mathrm{m}^{-3}\right)$} & \multicolumn{2}{c}{$\mathrm{Ca}^{2+}\left(\mathrm{ng} \mathrm{m}^{-3}\right)$} & \multicolumn{3}{c}{$\mathrm{Cl}^{-}\left(\mathrm{ng} \mathrm{m}^{-3}\right)$} \\
& $\mathrm{D}(\mu \mathrm{m})$ & Min & Med & Max & Min & Med & Max & Min & Med & Max & Min & Med & Max & Min & Med & Max \\
\hline FW & $0.05-0.14$ & 0 & 16 & 75 & 9 & 30 & 151 & 0.5 & 2 & 4 & 9 & 37 & 190 & 7 & 31 & 145 \\
& $0.14-0.42$ & 8 & 34 & 103 & 26 & 96 & 172 & 1 & 3 & 8 & 2 & 56 & 388 & 31 & 130 & 659 \\
& $0.42-1.20$ & 16 & 81 & 151 & 32 & 144 & 344 & 1 & 6 & 26 & 35 & 137 & 400 & 32 & 403 & 2297 \\
& $1.20-3.50$ & 16 & 100 & 360 & 10 & 51 & 208 & 2 & 19 & 46 & 44 & 415 & 843 & 18 & 205 & 810 \\
& $3.50-10.0$ & 22 & 104 & 846 & 11 & 24 & 150 & 3 & 17 & 60 & 203 & 398 & 956 & 24 & 124 & 1125 \\
\hline SS & $0.05-0.14$ & 2 & 7 & 17 & 3 & 14 & 33 & 1 & 2 & 4 & 13 & 43 & 97 & 5 & 10 & 29 \\
& $0.14-0.42$ & 3 & 13 & 34 & 8 & 34 & 65 & 2 & 3 & 4 & 6 & 45 & 143 & 5 & 8 & 54 \\
& $0.42-1.20$ & 7 & 22 & 204 & 7 & 29 & 74 & 2 & 4 & 21 & 12 & 81 & 161 & 5 & 9 & 71 \\
& $1.20-3.50$ & 9 & 78 & 959 & 8 & 19 & 74 & 4 & 20 & 117 & 86 & 218 & 453 & 6 & 15 & 801 \\
& $3.50-10.0$ & 7 & 85 & 281 & 9 & 17 & 30 & 4 & 20 & 42 & 114 & 334 & 998 & 6 & 20 & 246 \\
\hline
\end{tabular}

\subsubsection{Chemical composition}

Minimum, median and maximum air concentrations for the analysed species as a function of impactor stages are presented in Tables $2 \mathrm{~b}-\mathrm{d}$.

As depicted in Figs. 5 and 6, inorganic species show quite a different trend of median mass concentration in the two periods. In $\mathrm{FW}$, their concentration greatly increases from stage $1\left(1.12 \mu \mathrm{g} \mathrm{m}^{-3}\right)$ to stage $3\left(13.16 \mu \mathrm{g} \mathrm{m}^{-3}\right)$, when inorganic species account for $60 \%$ of the total mass, and then decreases to a minimum at stage $5\left(1.94 \mu \mathrm{g} \mathrm{m}^{-3}\right)$. In $\mathrm{SS}$, inorganic median concentrations show a more homogeneous distribution among the different stages, with very low values $\left(0.57 \mu \mathrm{g} \mathrm{m}^{-3}\right)$ at stage 1 and comparable values at stages 2-3 and 4-5. As for the distribution of inorganic species, WSOC and WINC median mass concentrations exhibit in FW a pronounced peak at stage $3\left(4.40 \mu \mathrm{g} \mathrm{m}^{-3}-\mathrm{WSOC}\right.$; $3.25 \mu \mathrm{g} \mathrm{m}^{-3}$ WINC), while in SS comparable concentrations are found at stages 2-3 and 4-5 (Figs. 5 and 6).

A larger contribution of carbonaceous species to the aerosol mass is observed in the submicron size range. In fact, as shown in Figs. 5 and 6, the percentage of WSOC and WINC decreases linearly from stage 1 to stage 5 . On the contrary, inorganic compounds do not exhibit such a linear trend and their contribution to the total mass reaches the maximum value at stages 2 and 3 .

Figures 5 and 6 also show that the unknown fraction has a similar trend in both periods, strongly dependent on particle size. The unknown fraction accounts for a few percent of the total mass in the fine aerosol size range (stages 1-3), where mass closure is practically achieved $\left(0.62 \mu \mathrm{g} \mathrm{m}^{-3}\right.$ in both periods, corresponding to $2 \%$ of the total mass in FW and $6 \%$ in $\mathrm{SS}$ ); higher percentages of unknown species are found in the coarse aerosol fraction $\left(5.89 \mu \mathrm{g} \mathrm{m}^{-3}\right.$, ca. $32 \%$ of the total mass in FW and $3.51 \mu \mathrm{g} \mathrm{m}^{-3}$, ca. $49 \%$ in SS). The increase of the unknown fraction with particle size is due to soil-derived insoluble species not determined in this study. A similar trend has already been reported in other continental areas by Neusüss et al. (2000), Temesi et al. (2001) and Kerminen et al. (2001).

For each impactor stage, the ion balance was also evaluated (Fig. 7). Cation-to-anion ratios, calculated in $\mu \mathrm{eq}^{-3}$, can be used to test the acidity of aerosol particles. The ion balance does not take into account the $\mathrm{H}^{+}$concentration, since $\mathrm{pH}$ was not measured in our samples. Therefore, cation-to-anion ratios below unity are indicative of an acidic nature of the collected particles, while cation-to-anion ratios above unity indicate the presence of anions not revealed by our analysis. Values around unity (0.99-1.07) were generally found for particles in the fine size range, regardless of season. Values above unity (1.2-1.55) were instead observed for particles in the supermicron size range, which can be related to the presence of carbonates and other soil-derived alkaline compounds (Fig. 7). This is consistent with the mass closure results and with the higher contribution of the unknown species to the coarse aerosol fraction. In the following discussion, the trend of inorganic ions and carbonaceous compounds will be reported, with reference to their median concentrations.

In both periods, inorganic ions represent a substantial part of the total mass, ranging between $30 \%$ and $60 \%$, depending on the stage. The main inorganic species are $\mathrm{NH}_{4}^{+}, \mathrm{NO}_{3}^{-}$ and $\mathrm{SO}_{4}^{2-}$ (Fig. 8 and Table 2b), which together account for more than $90 \%$ of the total inorganic ionic content of the fine aerosol fraction and ca. $65 \%$ of the coarse fraction. The median concentrations of inorganic species are higher during the FW period at all stages. Minima are observed at stages 1 and 5 , and maxima at stage 3 . However, concentrations at stages 2 and 3 are comparable in the SS period. Nitrate is the main inorganic component in $\mathrm{FW}$ and is preferentially distributed in the fine size range $(77 \%)$. However, nitrate 

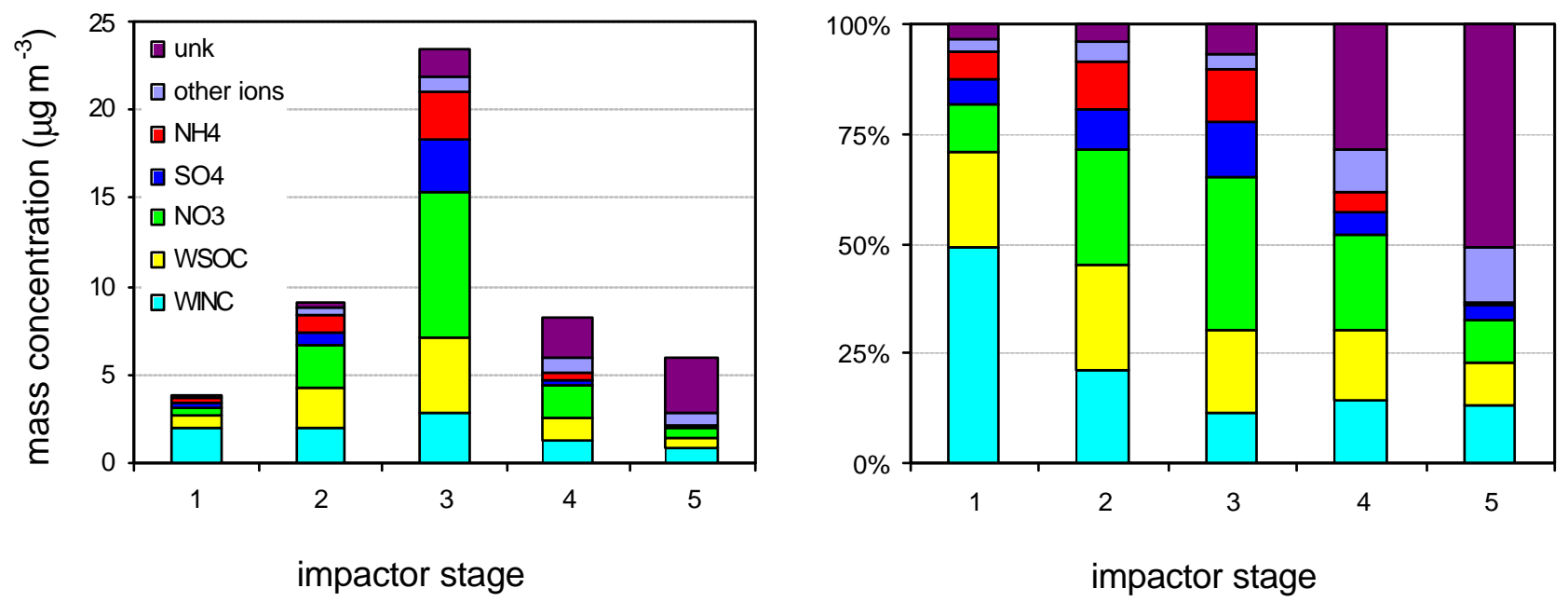

Fig. 5. Size segregated aerosol chemical composition: median concentrations $\left(\mu \mathrm{g} \mathrm{m}^{-3}\right)$ and percentage contribution of inorganic compounds $\left(\mathrm{SO}_{4}^{2-}, \mathrm{NO}_{3}^{-}, \mathrm{NH}_{4}^{+}\right)$, other ions, water soluble (WSOC) and insoluble (WINC) organic species to the aerosol mass in the FW period. Unk represents the difference between total mass, measured by gravimetry, and total analysed mass. Impactor stages refer to the following size ranges: 1) $0.05-0.14 \mu \mathrm{m}$; 2) $0.14-0.42 \mu \mathrm{m}$; 3) $0.42-1.2 \mu \mathrm{m}$; 4) $1.2-3.5 \mu \mathrm{m}$; 5) 3.5-10 $\mu \mathrm{m}$.
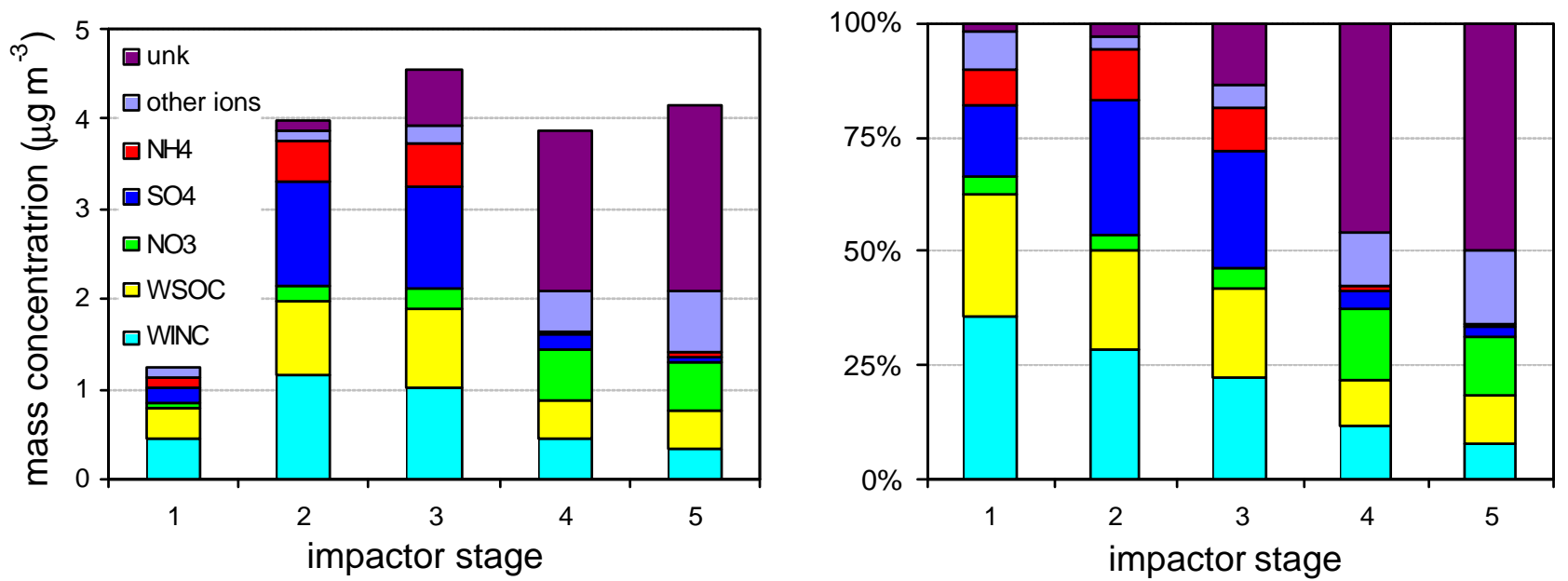

Fig. 6. Size segregated aerosol composition: median concentration $\left(\mu \mathrm{g} \mathrm{m}^{-3}\right)$ and percentage contribution of inorganic compounds $\left(\mathrm{SO}_{4}^{2-}\right.$, $\mathrm{NO}_{3}^{-}, \mathrm{NH}_{4}^{+}$), other ions, water soluble (WSOC) and insoluble (WINC) organic species to the aerosol mass in the SS period. Unk represents the difference between total mass, measured by gravimetry, and total analysed mass. Impactor stages refer to the following size ranges: 1) 0.05-0.14 $\mu \mathrm{m}$; 2) 0.14-0.42 $\mu \mathrm{m}$; 3) 0.42-1.2 $\mu \mathrm{m}$; 4) 1.2-3.5 $\mu \mathrm{m}$; 5) 3.5-10 $\mu \mathrm{m}$.

shows lower concentrations in SS and is mainly found (70\%) in the coarse fraction (stages 4 and 5).

Minor inorganic components are $\mathrm{Na}^{+}, \mathrm{K}^{+}, \mathrm{Mg}^{2+}, \mathrm{Ca}^{2+}$ and $\mathrm{Cl}^{-}$(Fig. 9 - Table 2d). Their contribution to total mass is lower than $5 \% . \mathrm{Na}^{+}, \mathrm{Mg}^{2+}$ and $\mathrm{Ca}^{2+}$ are preferentially distributed in the coarse size range and show similar concentration at all stages in both periods. The $\mathrm{Cl}^{-}$concentrations are higher in the FW period, with maxima at stage 3 and minima at stage 1 , while in the SS period most of the $\mathrm{Cl}^{-}$ mass is found in the coarse fraction. $\mathrm{K}^{+}$shows higher concentrations in the fine fraction in the $\mathrm{FW}$ period, indicating possible biomass combustion sources (Andreae, 1983; Cofer et al., 1991).
Table $2 \mathrm{c}$ reports TC, BC, WINC and WSOC minimum, median and maximum concentrations. As already observed, all carbonaceous species are preferentially distributed in the fine aerosol fraction. Figure 10 shows that TC, BC, WINC and water-soluble $\mathrm{OC}$ have a similar trend, with minima at stage 5, maxima at stage 3 in FW, and comparable concentration at stages 2 and 3 in SS. The contribution of all carbonaceous species to the total mass decreases as particle size increases, especially for WINC (from $40 \%$ to $10 \%$ ) and BC (from $20 \%$ to $1 \%$ ).

Similar mass distributions of the main organic and inorganic compounds in the fine and coarse size ranges and similar seasonal trends have already been observed in other 

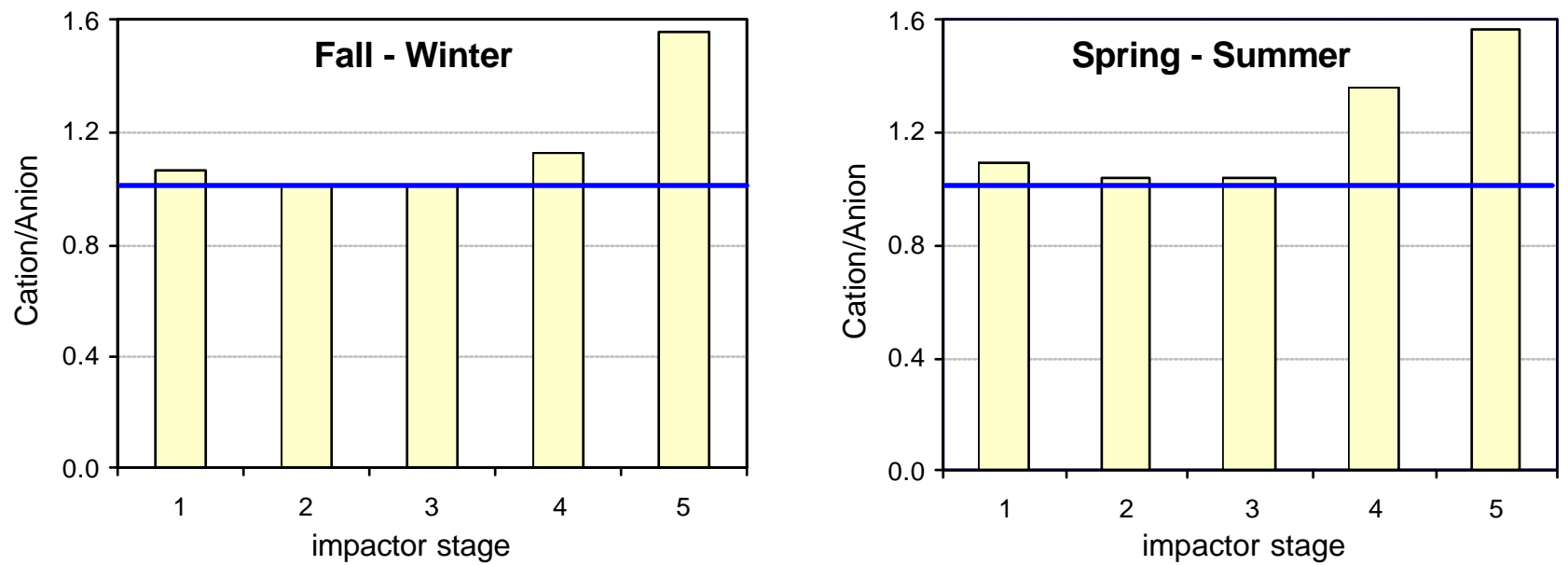

Fig. 7. Aerosol cation-to-anion ratios as a function of particle size in the FW and SS periods. The blue line represents unit ratio. Impactor stages refer to the following size ranges: 1) $0.05-0.14 \mu \mathrm{m}$; 2) $0.14-0.42 \mu \mathrm{m}$; 3) $0.42-1.2 \mu \mathrm{m}$; 4) $1.2-3.5 \mu \mathrm{m}$; 5) $3.5-10 \mu \mathrm{m}$.
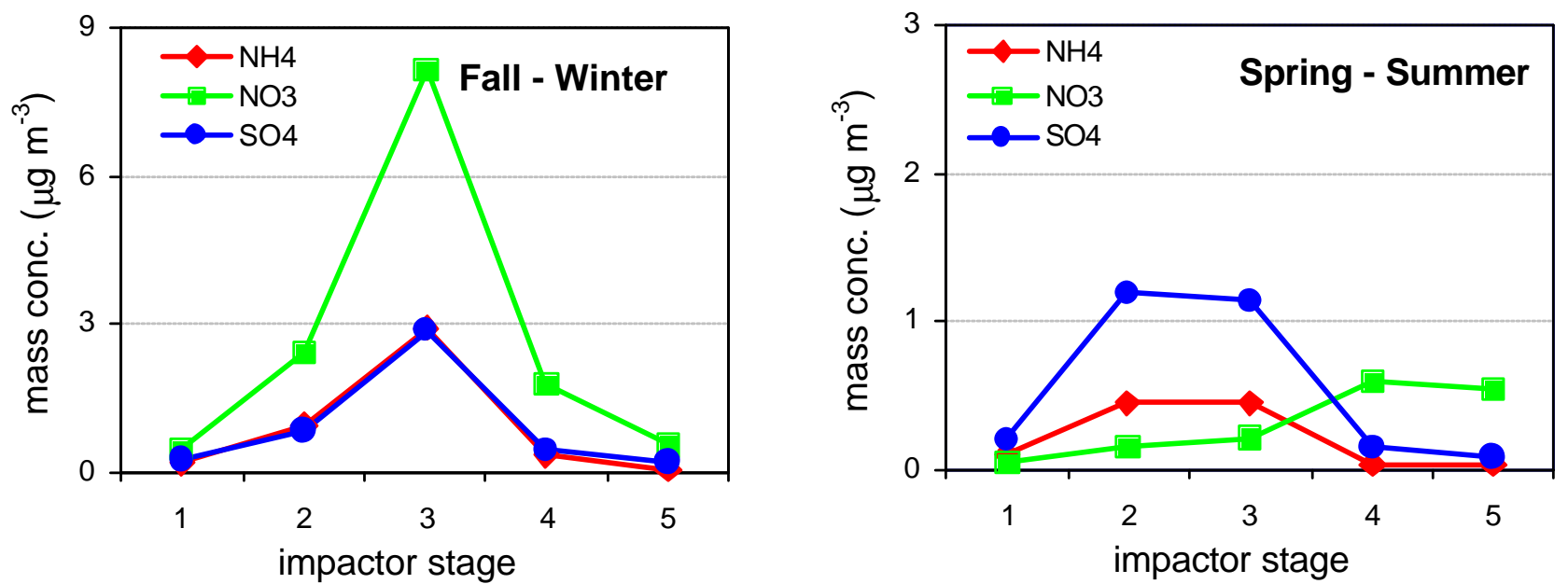

Fig. 8. Median concentration of aerosol main inorganic ions as a function of particles size in the FW and SS periods. Impactor stages refer to the following size ranges: 1) $0.05-0.14 \mu \mathrm{m}$; 2) $0.14-0.42 \mu \mathrm{m}$; 3) 0.42-1.2 $\mu \mathrm{m}$; 4) $1.2-3.5 \mu \mathrm{m}$; 5$) 3.5-10 \mu \mathrm{m}$.

polluted continental areas, such as the industrialised Leipzig basin, Germany (Heintzenberg et al., 1998), Hong Kong (Zhuang et al., 1999) and Chicago (Offenberg et al., 2000).

It should also be noted that the composition of fine particles in Bologna, in terms of air concentrations and seasonal trends is consistent with that observed at S. Pietro Capofiume, a rural site ca. $40 \mathrm{~km}$ from the city (Zappoli et al., 1999; Decesari et al., 2001). This observation suggests that formation, growth, processing and removal mechanism of aerosol particles occur on a regional scale in the Po Valley, due to homogeneous meteorological conditions and diffuse pollutant sources.

HPLC analysis of the aerosol extracts (Decesari et al., 2001) allowed the determination of the relative composition of water soluble organic compounds at each impactor stage. Table 3 summarises the measured air concentrations of neu- tral compounds, mono-/di-acids and polyacids for both FW and SS seasons. Due to the smaller amount of samples collected during the SS period, only three samples could be analysed by the HPLC technique (samples collected on 16 May, 22 and 24 August). The three separated chromatographic fractions follow the same size distribution as total WSOC (Fig. 11). Neutral compounds usually occur at lower concentrations compared to acidic ones, accounting for 15 to $40 \%$ of the sum of the three fractions. The percentage is higher during the FW season (26 to $36 \%$ on average, depending on stage), compared to the three SS samples (15 to $25 \%$ ). However, it should be noted that higher relative concentrations of neutral compounds are encountered only from October to December (32 to $44 \%$ of the sum of the three classes), whereas from January to March this fraction (22 to $30 \%$ ) does not differ significantly from the SS case. This 

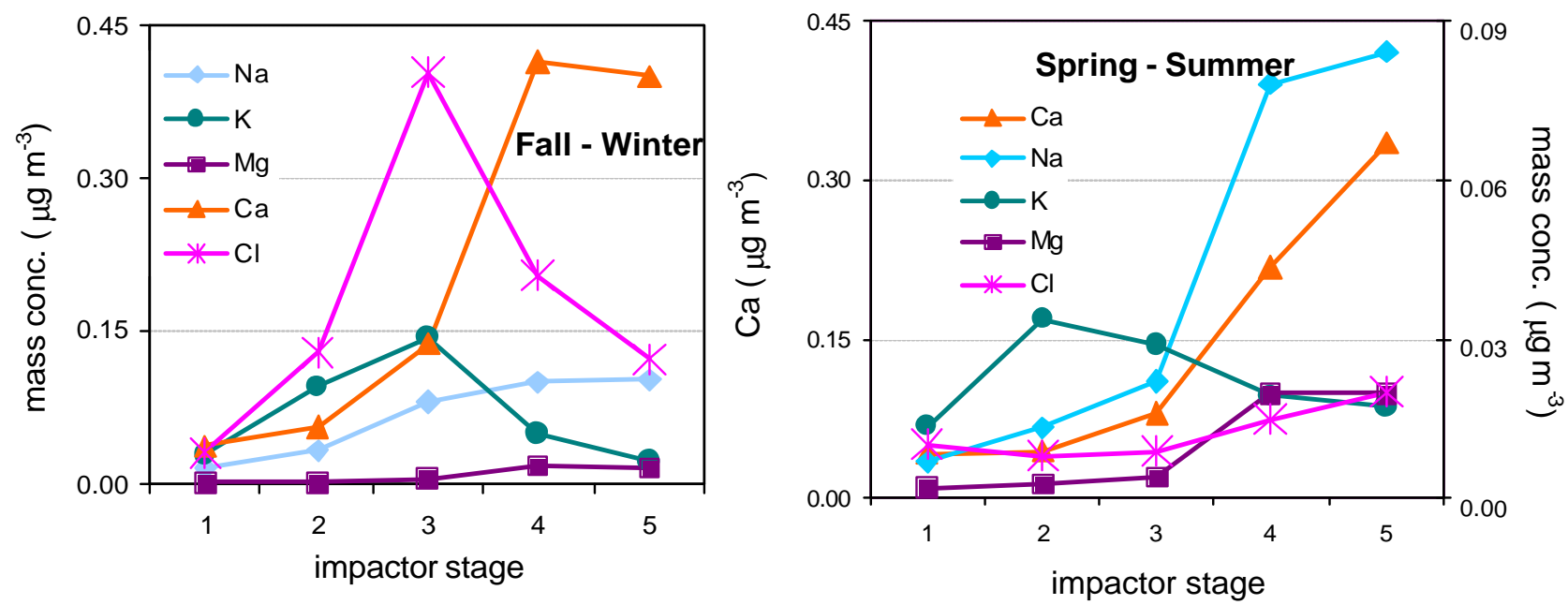

Fig. 9. Median concentration of aerosol minor inorganic ions as a function of particles size in the FW and SS periods. Impactor stages refer to the following size ranges: 1) $0.05-0.14 \mu \mathrm{m}$; 2) $0.14-0.42 \mu \mathrm{m}$; 3) 0.42-1.2 $\mu \mathrm{m}$; 4) $1.2-3.5 \mu \mathrm{m}$; 5) $3.5-10 \mu \mathrm{m}$.
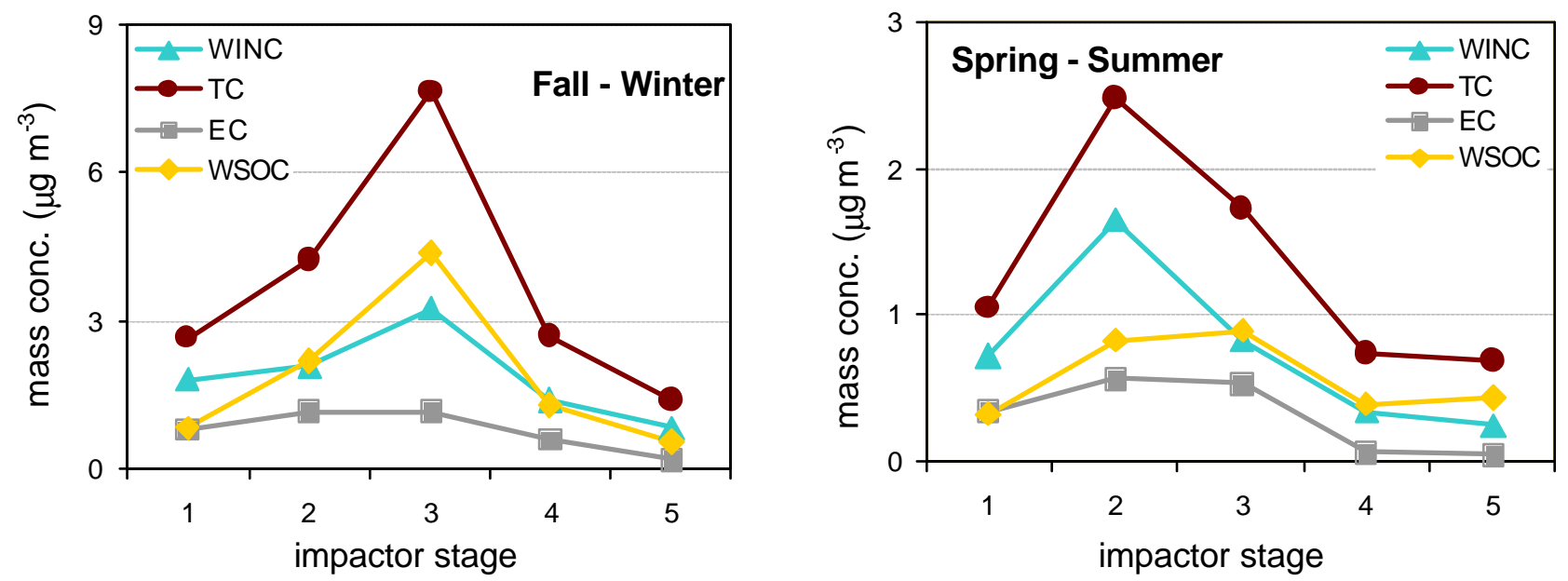

Fig. 10. Median concentrations of carbonaceous aerosol species as a function of particles size: in the FW and SS periods. Impactor stages refer to the following size ranges: 1) $0.05-0.14 \mu \mathrm{m}$; 2) $0.14-0.42 \mu \mathrm{m}$; 3) $0.42-1.2 \mu \mathrm{m}$; 4) $1.2-3.5 \mu \mathrm{m}$; 5) $3.5-10 \mu \mathrm{m}$.

is in agreement with the unique pattern observed during the fall season at the San Pietro Capofiume station (Decesari et al., 2001). The acidic compounds contain mono/di-acids and polyacids in comparable amounts, but the former are systematically dominant throughout the year, accounting for 60 to $70 \%$ of the total acidic compounds, with the higher percent contribution in the coarse stages.

3.3 Functional group analysis of the water soluble organic compounds

Figure 12 shows the HNMR spectra of the five impactor stages of a sample collected in November 2000 in polluted conditions (total mass $=55 \mu \mathrm{g} \mathrm{m}^{-3}$ ). Individual water soluble organic compounds were identified, based on their chem- ical shift (Decesari et al., 2000, 2001). The most important compound identified is levoglucosan, accounting for the sharp peaks between 3.3 and $5.4 \mathrm{ppm}$ as marked in the figure. Levoglucosan is detectable for particle sizes up to $3.5 \mu \mathrm{m}$, and is enriched in the $0.42-1.2 \mu \mathrm{m}$ interval. Levoglucosan is an unambiguous tracer of cellulose combustion and, due to its chemical stability, can accumulate onto fine particles and be transported over long distances ( $\mathrm{Si}$ moneit et al., 1999). Biogenic WSOC were identified in all size-fractions on the basis of the chemical shifts $\left(\delta_{H}\right)$ reported by Suzuki et al. (2001) and Decesari et al. (2001): trimethylamine $\left(\delta_{H}=2.90\right)$; methansulfonate $\left(\delta_{H}=2.81\right)$ and dimethylamine $\left(\delta_{H}=2.72\right)$. A number of sources, both natural and anthropogenic, may produce other identified WSOC (acetic acid, formic acid, succinic acid). Most 
Table 3. Minimum, median and maximum concentrations of neutral compounds (NC), mono-/di-acids (MDA) and polyacids for the five size intervals in the cold (FW) and the hot (SS) season. Statistics of the WSOC content of the samples are also reported in the first column. The range of variation is not reported for the SS period since a complete HPLC analysis was performed for three samples only (see text). All concentrations are reported in $\mu \mathrm{gC} \mathrm{m}{ }^{-3}$.

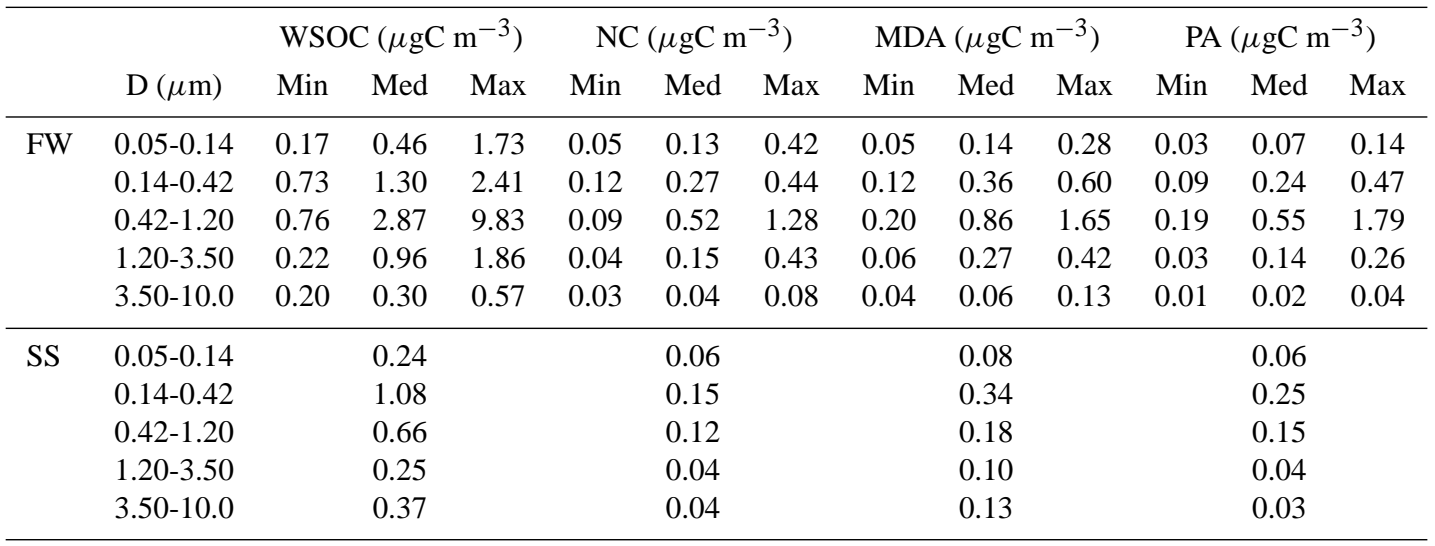
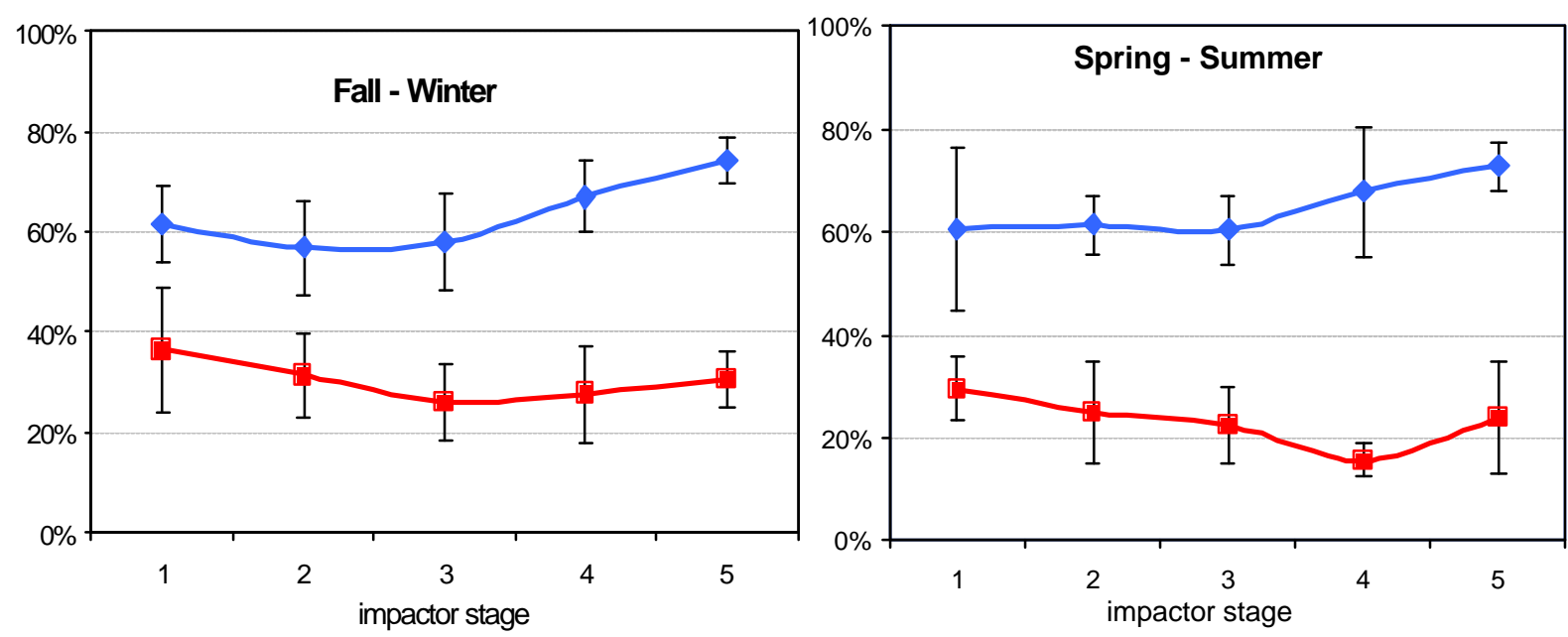

Fig. 11. Size segregated WSOC composition during the FW and SS seasons determined by HPLC analysis. The figure reports average and standard deviations for the ratio between neutral compounds and the sum of the three fractions (red line, squares) and for the percentage of mono/di-acids with respect to the total acidic fraction (blue line, diamonds). Impactor stages refer to the following size ranges: 1) 0.05-0.14 $\mu \mathrm{m}$; 2) 0.14-0.42 $\mu \mathrm{m}$; 3) 0.42-1.2 $\mu \mathrm{m}$; 4) 1.2-3.5 $\mu \mathrm{m}$; 5) 3.5-10 $\mu \mathrm{m}$.

HNMR signals could not be resolved and attributed to individual compounds, allowing only for a more general characterization based on functional group analysis. The main functional groups identified can be divided into four categories: $\mathrm{H}-\mathrm{Ar}$, aromatic rings; $\mathrm{H}-\mathrm{C}-\mathrm{O}$, aliphatic alcohols and ethers; $\mathrm{H}-\mathrm{C}-\mathrm{C}=$, aliphatic groups bound to unsaturated structures; $\mathrm{H}-\mathrm{C}$, purely aliphatic groups. The relative composition of WSOC with respect to the above functional groups shows minor variations for particle sizes up to $3.5 \mu \mathrm{m}$, whereas the coarsest size-interval is enriched in purely aliphatic moieties and is less aromatic. This is in agreement with the HNMR data from the size-segregated urban aerosol samples from Kobe City (Suzuki et al., 2001).
3.4 Functional group analysis and structural properties of water soluble organic compounds

Fuzzi et al. (2001) showed that functional group analysis performed by HNMR can be used to determine the general structural properties of aerosol organic compounds. Following the same approach, the concentration of functional groups determined by HNMR in the test sample was used to convert their hydrogen content, quantitatively determined by the HNMR analysis, into the corresponding carbon content, based on specific theoretical $\mathrm{C} / \mathrm{H}$ molar ratios. Table 4 summarises the functional group air concentration of $\mathrm{H}$ and $\mathrm{C}$, where the aromatic moieties were calculated by difference (Fuzzi et al., 
Table 4. Functional group air concentrations of water soluble organic compounds of sample 291100 for the five size intervals. Molar hydrogen concentrations are determined by HNMR analysis, whereas carbon concentration were calculated assuming $\mathrm{C} / \mathrm{H}$ ratios specific for each category (Fuzzi et al., 2001). The range of variation of carbon concentrations was estimated according to the uncertainties on the $\mathrm{C} / \mathrm{H}$ values. Carbonyls (keto and carboxylic groups) and their alpha carbon atoms are included here in a single category $(\mathrm{H}-\mathrm{C}-\mathrm{C}=\mathrm{O})$.

\begin{tabular}{cccccccccc}
\hline & \multicolumn{2}{c}{ WSOC } & \multicolumn{2}{c}{$\mathrm{Ar}$} & \multicolumn{2}{c}{$\mathrm{H}-\mathrm{C}-\mathrm{C}=\mathrm{O}$} & \multicolumn{2}{c}{$\mathrm{H}-\mathrm{C}$} \\
$\mathrm{D}(\mu \mathrm{m})$ & $\mu \mathrm{gC} \mathrm{m}^{-3}$ & $\mu \mathrm{molH} \mathrm{m}^{-3}$ & $\mu \mathrm{gC} \mathrm{m}^{-3}$ & $\mu \mathrm{molH} \mathrm{m}^{-3}$ & $\mu \mathrm{gC} \mathrm{m}^{-3}$ & $\mu \mathrm{molH} \mathrm{m}^{-3}$ & $\mu \mathrm{gC} \mathrm{m}^{-3}$ & $\mu \mathrm{molH} \mathrm{m}^{-3}$ & $\mu \mathrm{gC} \mathrm{m}^{-3}$ \\
\hline $0.05-0.14$ & 0.38 & 0.002 & $0.20(0.14-0.25)$ & 0.004 & $0.04(0.02-0.05)$ & 0.007 & $0.07(0.05-0.13)$ & 0.011 & $0.07(0.05-0.07)$ \\
$0.14-0.42$ & 1.20 & 0.007 & $0.64(0.46-0.81)$ & 0.013 & $0.14(0.08-0.16)$ & 0.020 & $0.21(0.14-0.36)$ & 0.036 & $0.22(0.17-0.22)$ \\
$0.42-1.20$ & 2.01 & 0.017 & $0.70(0.28-1.11)$ & 0.035 & $0.38(0.21-0.42)$ & 0.046 & $0.49(0.33-0.84)$ & 0.074 & $0.44(0.35-0.46)$ \\
$1.20-3.50$ & 0.58 & 0.004 & $0.29(0.19-0.38)$ & 0.007 & $0.08(0.04-0.08)$ & 0.011 & $0.11(0.08-0.19)$ & 0.018 & $0.11(0.08-0.11)$ \\
$3.50-10.0$ & 0.12 & 0.001 & $0.00(0.00-0.04)$ & 0.004 & $0.04(0.02-0.04)$ & 0.003 & $0.04(0.02-0.06)$ & 0.008 & $0.05(0.04-0.05)$ \\
\hline
\end{tabular}

2001). Ketones and carboxylic acids, unlike what was done in Fuzzi et al. (2001), were estimated here as a whole, considering a $\mathrm{C} / \mathrm{H}$ molar ratio of $0.38(0.2-1.0)$ between the carbon atoms of $\mathrm{C}=\mathrm{O}$ groups and their alpha hydrogen atoms. It is noticeable that the aromatic moieties account for only a few percentages of the total hydrogen content, but up to $50 \%$ of TOC, indicating that aromatic rings are highly condensed and/or substituted.

The representation of the composition of water soluble organic compounds as a simple budget of functional groups, each characterised by an average structure and molar mass, allows us to derive general structural properties for these compounds, such as the mass/carbon ratio. The assumptions made to assign an average molar mass to each functional group are the same used for estimating the $\mathrm{C} / \mathrm{H}$ ratios (Fuzzi et al., 2001). In addition, carboxylic and hydroxyl substituents are considered to occur on aromatic rings, as expected by the observed range of chemical shifts for Ar-H (Decesari et al., 2000). Residual uncertainty associated with the molar mass of aromatic groups and carbonyls (comprising ketons and carboxylic groups) makes the mass/carbon ratio for WSOC vary from 1.7 to 2.3. An average organic mass vs. carbon ratio of 1.8 was used to transform the WSOC carbon content into the corresponding mass (see Sect. 3.1). The same ratio was used by Temesi et al. (2001), whereas Turpin et al. (2000) proposed higher values for the water soluble organic compounds, implying a more pronounced polar character of the constituents. On the other hand, the HNMR analysis of sample 291100 clearly indicates that compounds bearing purely aliphatic moieties ( $\mathrm{H}-\mathrm{C}$ groups) account for a significant fraction of total water soluble organic compounds, even if more polar compounds, such as $\mathrm{C}_{2}-\mathrm{C}_{5}$ - dicarboxylic acids, are the most common species identified in the aerosol soluble fraction and reported in literature (see e.g. Kerminen et al., 2000).

As mentioned above, water soluble organic compounds are not characterised at the molecular level in this paper. Thus no information is available on their possible sources and transformations in the atmosphere. However, the average chemical features provided by HNMR can be com-
Table 5. Organic functional group concentrations normalized to the total carbon amount (ROF/C) derived for sample 291100 from HNMR data. The modelled composition of water soluble organic compounds for a typical urban area is also reported based on data from Aumont et al. (2000). Explanation of the symbols: $-\mathrm{C}(\mathrm{O}) \mathrm{OH}$ carboxylic groups; $>\mathrm{C}=\mathrm{O}$ keto groups; - $\mathrm{CHO}$ aldehydes; $-\mathrm{OH}$ alcohols

\begin{tabular}{ccc}
\hline \multirow{2}{*}{ Functional groups } & \multicolumn{2}{c}{ ROF/C } \\
& This study & Aumont et al. \\
\hline Total & $34-54 \%$ & $50-70 \%$ \\
$-\mathrm{C}(\mathrm{O}) \mathrm{OH}$ & $8-20 \%$ & $<1 \%$ \\
$>\mathrm{C}=\mathrm{O}$ & $4-11 \%$ & $5-20 \%$ \\
$-\mathrm{CHO}$ & $<\mathrm{d} .1$. & $\sim 10 \%$ \\
$-\mathrm{OH}$ & $22-27 \%$ & $20-30 \%$ \\
other polar groups & $<\mathrm{d} .1$. & $\sim 5 \%$ \\
\hline
\end{tabular}

pared with the predictions of models of water soluble organic compound formation in a polluted industrialized area. Aumont et al.(2000) modelled the water soluble organic compound production by gas-to-particle conversion in urban and rural environments, resulting in mean air concentrations of about $1-4 \mu \mathrm{gC} \mathrm{m}^{-3}$. According to the expected reaction pathways, these authors provided the functional group composition of the final mixtures of water soluble organic compounds, which can be compared directly with those derived from the present work. The modelled (Aumont et al., 2000) and measured (this work) water soluble organic compound functional group compositions are reported in Table 5. Organic functional group concentrations are normalised to the total carbon amount $(\mathrm{ROF} / \mathrm{C})$. The data reported for the real samples only refer to aliphatic functional groups and to the total aliphatic carbon content, since an accurate aromatic functional group characterisation is not provided by HNMR. On the other hand, Aumont et al. (2000) reported only aliphatic compounds as representative for the products of gas-to-particle conversion. Moreover, aliphatic 


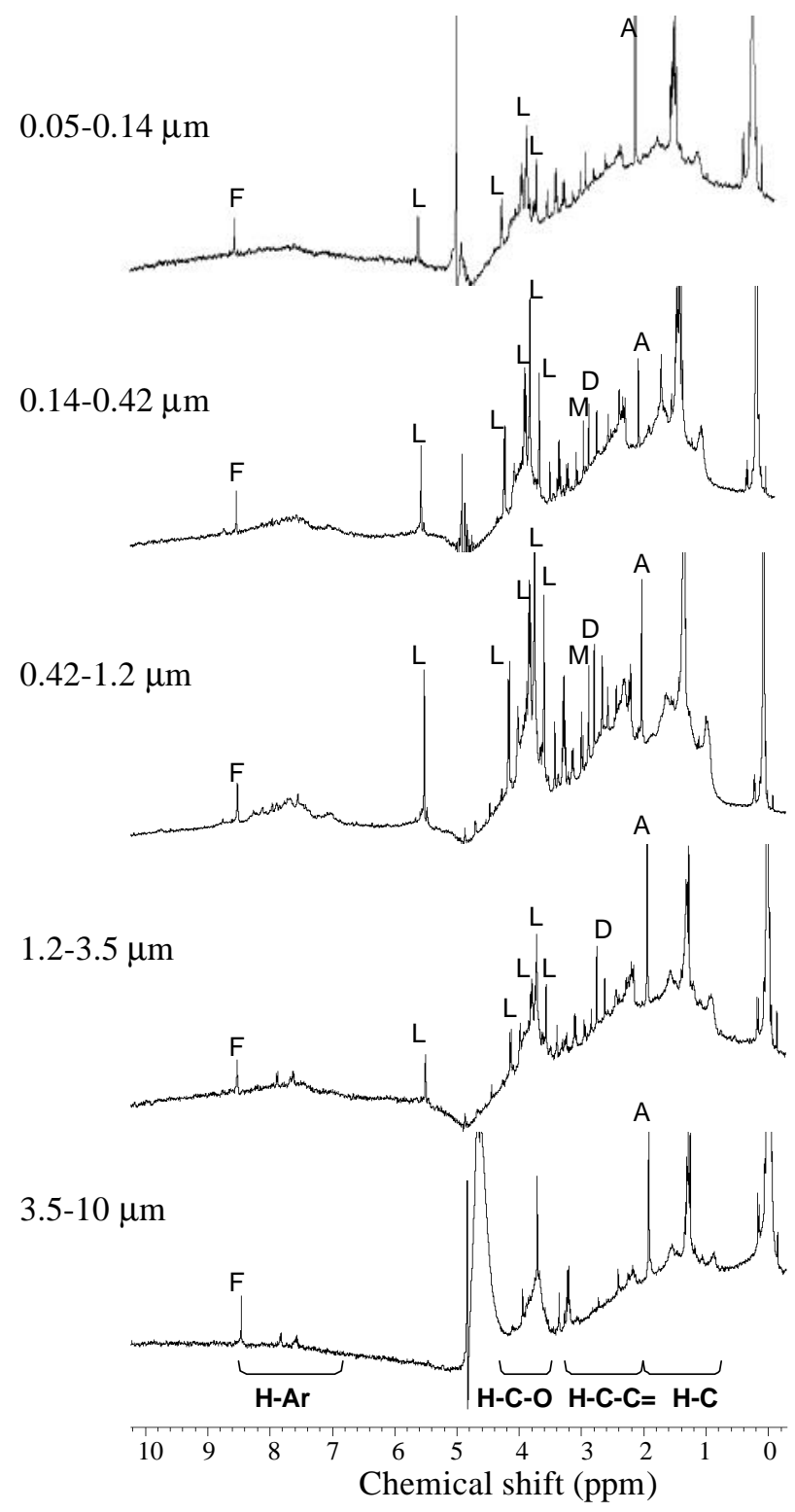

Fig. 12. HNMR spectra of the water extracts of the test sample collected in November (five impactor stages). Extracts were dried and re-dissolved in deuterated water and an internal standard $\left(\mathrm{Tsp} d_{4}\right)$ was added before analysis. The horizontal scale is the chemical shift $\left(\delta_{H}\right)$ referred to the internal standard. The peaks attributed to individual compounds are marked in the figure ("F": formate; "L": levoglucosan; "M": methansulfonate; "D": dimethylamine; "A": acetate). Four specific spectral regions are also identified at the bottom of the spectra. "H-C": purely alkylic protons; "H-C$\mathrm{C}=$ ": protons bound to aliphatic carbon atoms adjacent to unsaturated groups; "H-C-O": protons bound to oxygenated aliphatic carbon atoms; "Ar-H": aromatic protons. The region between 4.4 and $5.0 \mathrm{ppm}$ is disturbed by instrumental noise due to a residual signal of HDO. Spectra were recorded at $400 \mathrm{MHz}$. Details on the experimental conditions are provided in Decesari et al. (2000). carbonyls from HNMR (see Table 5) were split into keto- and carboxylic- groups, according to the relative concentrations of neutral versus acidic compounds for the test sample as determined by the HPLC analysis. Compared to the composition modelled by Aumont et al. (2000), the HNMR results indicate a lower degree of substitution of water soluble organic compounds, and thus a lower level of oxidation. Aumont et al. (2000) reported mainly oxygenated functional groups, in agreement with our findings. The measured hydroxyl content is comparable to the modelled one; on the other hand, aldehydes are not found in the aerosols we analysed in significant concentrations (see also Decesari et al., 2000, 2001). Moreover, carboxylic groups, which are the main functional groups present in the real aerosol sample, account for less than $1 \%$ carbon atoms in the modelled products of gas-toparticle conversion. Aumont et al. (2000) suggested that a much higher concentration of carboxylic groups (ROF/C up to $20-30 \%$ ) can be expected, if further oxidation processes in wet aerosols are taken into account. The same processes would lead to the consumption of aldehydic moieties via reaction with the $\mathrm{OH}$ radical. Unfortunately, the actual chemical composition of the end products of this reaction scheme is highly uncertain, due to the poor information available on the reactivity of water soluble organic compounds in wet aerosols. In conclusion, we can only report that the observed chemical composition of water soluble organic compounds in the aerosol samples from Bologna is not consistent with the hypothesis of a major contribution to their concentration from gas-to-particle conversion of anthropogenic VOCs, unless extensive oxidative reactions in the aqueous phase of aerosols is considered, for which information is not available.

\section{Conclusions}

A complete size segregated chemical characterisation was carried out for aerosol samples collected in the urban area of Bologna over a period of one year. Total mass, inorganic, and organic components were analysed and a detailed characterisation of WSOC was performed. The mass closure of the chemical species was reached with respect to the weighed mass in the submicron aerosol fraction, while a higher unknown fraction in the coarse aerosol range was attributed to soil-derived species not analysed in this experiment. The main inorganic components were ammonium, sulfate and nitrate, the former two exhibiting concentration maxima in the FW and SS periods in the fine aerosol fraction, the latter, nitrate, showing lower concentrations in SS and being mainly found $(70 \%)$ in the coarse fraction (stages 4 and 5).

Carbonaceous species were preferentially distributed in the fine aerosol fraction, with relative concentrations decreasing with increasing particle size. WSOC represents on average $50 \%$ of the total aerosol TC. The three main classes of compounds that constitute the total WSOC (neutral 
species, mono- and di-carboxylic acids) follow the same size distribution as total WSOC. Neutral compounds occur at lower concentrations compared to acidic ones in all size ranges. Mono- and di-carboxylic acids are the main organic acidic fraction, accounting for $60-70 \%$ of the total acidic compounds, with an higher percentage contribution in the coarse aerosol fraction. Full functional group analysis of WSOC by HNMR for one size segregated sample allowed the determination of an average mass to carbon ratio of 1.8. Comparison of the functional group analysis results by HNMR to model results simulating water soluble organic compound production by gas-to-particle conversion of anthropogenic VOCs (Aumont et al., 2000) showed that this pathway provides a minor contribution to water soluble organic compounds in the aerosol samples from the urban area of Bologna, unless oxidation in aqueous aerosol is taken into account to justify the higher carboxylic group content observed in real samples. In addition, tracer analysis (levoglucosan) suggests that biomass burning may represent an important primary source of WSOC in the Po Valley environment (Decesari et al., 2001).

The procedure reported in this paper allowed a full chemical characterisation of size-segregated aerosol samples which is, to our knowledge, the most complete reported in literature to date.

Acknowledgements. The Regional Environmental Agency (ARPAER, Sezione Provinciale di Bologna) is acknowledged for providing the $\mathrm{PM}_{10}$ data for the City of Bologna. M. Mircea was supported by ICTP Programme for Training and Research in Italian Laboratories, Trieste, Italy. This work was partly financed by Agenzia 2000 of C.N.R..

\section{References}

Andreae, M. O.: Soot carbon and excess fine potassium: long-range transport of combustion derived aerosols, Science, 220, 11481151, 1983.

Aumont, B., Madronich, S., Bey, I., and Tyndall, G. S.: Contribution of secondary VOC to the composition of aqueous atmospheric particles: A modelling approach. J. Atmos. Chem., 35, 59-75, 2000.

Cachier, H., Bremond, M. P., and Buat-Menard, P.: Determination of atmospheric soot carbon with a simple thermal method, Tellus, 41B, 379-390, 1989.

Cadle, S., Groblicki, P. J., and Stroup, D. P.: Automated carbon analyser for particulate samples, Anal. Chem., 52, 2201-2206, 1980.

Chow, J. C., Watson, J. G., Pritchett, L. C., Pierson, W. R., Frazier, C. A., and Purcell, R. G.: The DRI thermal/optical reflectance carbon analysis system: Description, evaluation and applications in U.S. air quality studies, Atmos. Environ., 27A, 1185-1201, 1993.

Cofer, W. R., Levine, J. S., Winstead, E. L., and Stocks, B. J.: Trace gas and particulate emissions from biomass burning in temperate ecosystems, in: Global Biomass Burning, (Eds) Levine, J. S., pp. 203-208, The MIT Press, Cambridge, 1991.
Decesari, S., Facchini, M. C., Fuzzi, S., and Tagliavini, E.: Characterization of water-soluble organic compounds in atmospheric aerosol: A new approach, J. Geophys. Res., 105, 1481-1489, 2000.

Decesari, S., Facchini, M. C., Matta, E., Lettini, F., Mircea, M., Fuzzi, S., Tagliavini, E., and Putaud, J.-P.: Chemical features and seasonal trend of water soluble organic compounds in the Po Valley fine aerosol, Atmos. Environ., 35, 3691-3699, 2001.

Fuzzi, S., Laj, P., Ricci, L., Orsi, G., Heintzenberg, J., Wendisch, M., Yuskiewicz, B., Orsini, D., Schwanz, M., Wiedensohler, A., Stratmann, F., Berg, O. H., Swietlicki, E., Frank, G., Martinsson, B. G., Günther, A., Dierssen, J., Schell, D., Jaeschke, W., Berner, A., Dusek, U., Galambos, Z., Kruisz, C., Mesfin, S. N., Wobrock, W., Arends, B., and ten Brink, H.: Overview of the Po valley fog experiment 1994 (CHEMDROP), Contrib. Atmos. Phys., 71, 319, 1998.

Fuzzi, S., Decesari, S., Facchini, M. C., Matta, E., Mircea, M., and Tagliavini, E.: A simplified model of the water soluble organic component of atmospheric aerosols, Geophys. Res. Lett., 28, 4079-4082, 2001.

Gelencsér, A., Hoffer, A., Molnar, A., Krivacsy, Z., Kiss, G., and Meszaros, E.: Thermal behaviour of carbonaceous aerosol from continental background site, Atmos. Environ., 34, 823-831, 2000.

Heintzenberg, J., Müller, K., Birmili, W., Spindler, G., and Wiedensohler, A.: Mass-related aerosol properties over the Leipzig basin, J. Geophys. Res., 103, D11, 13 125-13 135, 1998.

Huntzicker, J. J., Johnson, R. L., Shah, J. J., and Cary, R. A.: Analysis of organic and elemental carbon in ambient aerosols by a thermal-optical method, in: Particulate Carbon: Atmospheric Life Cycle, (Eds) Wolff, G. T. and Klimisch, R. L., pp. 79-88, Plenum, New York, 1982.

Jacobson, M. C., Hansson, H.-C., Noone, K. J., and Charlson, R. J.: Organic atmospheric aerosols: Review and state of the science, Rev. Geophys., 38, 267-294, 2000.

Kerminen, V.-M., Hillamo, R., Teinila, K., Pakkanen, T., Allegrini, I., and Sparapani, R.: Ion balances of size-resolved tropospheric aerosol samples: implications for the acidity and atmospheric processing of aerosols, Atmos. Environ., 35, 5255-5265, 2001.

Mayol-Bracero, O. L., Guyon, P., Graham, B., Andreae, M. O., Decesari, S., Facchini, M. C., and Artaxo, P.: Black carbon, Organic carbon and Water-Soluble Organic Compounds in Biomass smoke particles over the Amazon Basin, J. Geophys. Res., 107, 8091, doi.: 10.1029/2001JD000522, 2002.

Neusüss, C., Pelzing, M., Plewka, A., and Herrmann, H.: A new analytical approach for size-resolved speciation of organic compounds in atmospheric aerosol particles: methods and first results, J. Geophys. Res., 105, 4513-4527, 2000.

Novakov, T., Hegg, D. A., and Hobbs, P. V.: Airborne measurements of carbonaceous aerosols on the East Coast of the United States, J. Geophys. Res., 102, D25, 30 023-30 030, 1997.

Offenberg, J. H. and Baker, J. E.: Aerosol size distribution of elemental and organic carbon in urban and over-water atmospheres, Atmos. Environ., 34, 1509-1517, 2000.

Putaud, J.-P., van Dingenen, R., Mangoni, M., Virkkula, A., Raes, F., Maring, H., Prospero, J. M., Swietlicki, E., Berg, O. H., Hillamo, R., and Mäkelä, T.: Chemical mass closure and assessment of the origin of the submicron aerosol in the marine boundary layer and the free troposphere at Tenerife during ACE2, Tellus, 52B, 141-168, 2000. 
Rogge, W. F., Mazurek, M. A., Hildemann, L. M., Cass, G. R., and Simoneit, B. R. T.: Quantification of urban organic aerosols at a molecular level: Identification, abundance and seasonal variation, Atmos. Environ., 27A, 1309-1330, 1993.

Saxena, P. and Hildemann, L. M.: Water-soluble organics in atmospheric particles: A critical review of the literature and application of thermodynamics to identify candidate compounds, J. Atmos. Chem., 24, 57-109, 1996.

Simoneit, B. R. T., Schauer, J. J., Nolte, C. G., Oros, D. R., Elias, V. O., Fraser, M. P., Rogge, W. F., and Cass G. R.: Levoglucosan, a tracer for cellulose in biomass burning and atmospheric particles, Atmos. Environ., 33, 173-182, 1999.

Suzuki, Y., Kawakami, M., and Akasaka, K.: 1H NMR application for characterizing water-soluble organic compounds in urban atmospheric particles, Environ. Sci. Technol., 35, 26562664, 2001.
Temesi D., Molnar, A., Meszaros, E., Feczko, T., Gelencser, A., Kiss, G., and Krivacsy, Z.: Size resolved chemical mass balance of aerosol particles over rural Hungary, Atmos. Environ., 35, 4347-4355, 2001.

Turpin, B. J., Saxena, P., and Andrews, E.: Measuring and simulating particulate organics in the atmosphere: problems and prospects, Atmos. Environ., 34, 2983-3013, 2000.

Zappoli, S., Andracchio, A., Fuzzi, S., Facchini, M. C. A., Gelencsér, A., Kiss, G., Krivácsy, Z., Molnár, A., Mészáros, E., Hansson, H. C., Rosman, K., and Zebühr, Y.: Inorganic, organic and macromolecular components of fine aerosol in different areas of Europe in relation to their water solubility, Atmos. Environ., 33, 2733-2743, 1999.

Zhuang, H., Chan, C. K., Fang, M., and Wexler, A.: Size distributions of particulate sulphate, nitrate and ammonium at a coastal site in Hong Kong, Atmos. Environ., 33, 843-853, 1999. 